\title{
Modelling Online Course Services and Comparison of its Major Providers
}

\author{
https://doi.org/10.3991/ijet.v13i01.7528 \\ Abdullah Alkaff, M. Nur Qomarudin( $\left.{ }^{(}\right)$, Sylmina D. Alkaff, Yusuf Bilfaqih \\ Institute of Technology Sepuluh Nopember (ITS), Surabaya, Indonesia \\ alfiyahibnumalik@gmail.com
}

\begin{abstract}
Online course has created many success stories since its inceptions. It has opened opportunities for learners, instructors, universities, companies, and other organizations to fulfill their needs in education and even creates new needs which previously are unthinkable possible. Online course providers have central roles in bridging and fulfilling the needs of these many parties. This paper modelled online course services based on identification of the needs for online course in a form of activity flow diagrams. The model also includes the context diagram of stakeholders involved and the entity relationship diagram. Primary service components of major online course providers and activities involved in each service are identified. Based on these service components, a comparison of services offered by major online course providers is given. The needs of services that are least or not yet satisfied from online course providers are also identified to show that there are still opportunities to enhance the current services.
\end{abstract}

Keywords-online course, needs identification, service models, comparison study

\section{Introduction}

According to a New York Times best seller book, Second Machine Age, we live in an age where automation makes human and software-driven machines substitutes, rather than complements. In order to survive in this new age, it is necessary for human to educate themselves to be more creative. Pursuing education in the most excellent environment is the best option to acquire such creativity. Unfortunately, the likelihood to receive the best education for every single person is often limited by financial ability or geographical reachability. The demands for college education therefore are increasing but they are expensive and cause many people to go into debt [1].

Fortunately, several world-class universities have acknowledged this complication by sharing their course materials through publicly available online courses. Stanford University pioneered this option through Stanford Online in 2006. Since then, there are at least 21 other online course providers [2] with Coursera, Udacity, and edX currently dominating the market [3]. Recent data show the increase in numbers of 
providers and their online programs are also accompanied by the increase in enrolled participants [4].

There are at least three types of online courses available as of recently. Massive Open Online Course (MOOC) is the most popular one, allowing its participants to explore available courses for free. MOOC providers, such as Coursera, edX, and Udacity, establish a platform allowing any universities to publish their courses online. Closed Online Course (COC), on the other hand, is self-maintained by individual university to publish their courses. Harvard and Arizona State University Online Learning are the popular examples of this type. The term "closed" refers to the fact that registration fee is required to gain access to its available courses. The last type of online course, Online Degree (OD), focuses on providing a degree for its participants through a set of online courses. To achieve this goal, most OD providers, such as $2 \mathrm{u}$, collaborate with several universities to create a set of online courses required for a degree. However, there are several instances where OD provider arrange their own degree-earning courses, such as University of Phoenix.

Online course has been a popular research topic due to its rising trends. Aparicio et al. has identified the participants, technology, and services related to e-learning [5] and also presented the business model of various types of online courses [6]. Zhenghao et al. reported that most participant in online courses received career and educational benefits [7]. Onah et al. analyzed the dropout rate of online courses and the reasons behind it [8]. Dillahunt et al. has investigated which online course services providing more assistance for economically disadvantaged populations [9]. Additionally, the report by The Learning House, Inc. presents comprehensive data about online college trends and its key findings in 2017 [4]. However, none of the studies aims to identify the needs for online course and the available services to fulfill them.

The motivation of this study is to understand these needs and the service model designed to satisfy them. The first step is to identify the needs from many different user perspectives based on their motivation and goals. Based on this finding, stakeholders involved in producing and delivering online course services can be identified, along with their relationships. This study is then continued to obtain the models of several types of online course services based on their activity flow showing how they fulfill the needs. Finally, comparison between several major providers is given.

\section{Needs for Online Courses}

Battushig, a 16 years old student from Mongolia, is the most exemplary story of how online course open possibilities for people from any country, age, and background to obtain the best education. He enrolled in a course by MIT through MOOC and achieved the perfect score. Due to his excellent achievement, Battushig was offered an admission to MIT with full scholarship [10]. His story is just one of many others revealing the existence of individuals with great potential and eagerness to learn but limited by access, time, and financial availability to pursue a formal education at the best universities [9]. Their motivations are simply seeking educational and/or career benefits [7]. Improved skill and knowledge are important goals in pursu- 
ing education, but some learners also seek a certificate of course completion to upgrade their resume. Nowadays, their goals are widely expanding into seeking specialization or professional/technical certification, degree, and ultimately landing job offer [4].

The presence of online course also satisfies the needs from instructor's perspective to reach wider audience and find brilliant perspective students. Professor Sebastian Thrun from Stanford University began to question his traditional lecture style with 200 students attending while there are billions of people around the world connected to the Internet [11]. When his first online course was attended by 160,000 students across the world, Thrun realized that none of his top 400 students were Stanford students, showing the many talents available that are not yet served.

In the nascent year of online course, American Council of Education approved several online courses as credits [12]. This approval motivates many universities to join partnership with online course providers to publish their courses [13], the latest of which is Penn State University with FutureLearn [14]. In this digital age, universities need to utilize online courses to either expand their impact across the globe [14, 15], search for best students across the world [10], or reduce the educational cost [16]. For example, Purdue University has acquired for-profit Kaplan University and transform it to non-profit to extend its reach into online and adult education [17]. These movements represent the increasing needs of universities to serve online course.

Company and other organization also requires the presence of online course for several purposes such as conducting online training for their employees [18], recruiting talented persons [19], and also offering some courses [20, 21]. Google, for example, collaborate with Udacity to hold one of its technical exam through Udacity [22] as well as creating preparation courses for the exam [23]. The needs for online course from many different perspectives are summarized in Table 1 . .

Table 1. Needs for Online Course

\begin{tabular}{|c|c|}
\hline Perspective & Needs \\
\hline Learner & $\begin{array}{l}\text { - Self-esteem/Skill development } \\
\text { - Course certificate } \\
\text { - Specialization certificate } \\
\text { - Technical certificate } \\
\text { - Degree } \\
\text { - Professional certificate } \\
\text { - Job }\end{array}$ \\
\hline Instructor & $\begin{array}{l}\text { - Reach greater audience for their courses } \\
\text { - Teach brilliant students }\end{array}$ \\
\hline University & $\begin{array}{l}\text { - Expand impact } \\
\text { - Reduce educational cost } \\
\text { - Look for best talents } \\
\text { - Offer courses and degree }\end{array}$ \\
\hline Company/ Organization & $\begin{array}{l}\text { - Employee training } \\
\text { - Recruit talents } \\
\text { - Offer courses }\end{array}$ \\
\hline Product Certifier & $\begin{array}{l}\text { - Offer preparation courses for technical certification } \\
\text { - Offer technical certification exam }\end{array}$ \\
\hline
\end{tabular}


This variety of needs motivates the necessity of providing and bridging those needs by establishing online course services. The needs for online course are expanding over time, opening new opportunities for other parties to collaborate and potentially enrich the perspective of needs. In other words, both well-established online course providers and new ones will always have a great chance to fill the gaps between the needs and the services provided and even to create new needs.

Learners' needs are the most crucial factor in online course services due to their central role in sustaining and boosting the popularity of online course providers. Learners have a variety of needs for online course in a sequence order which represents degree of difficulty. Most learners only participate in some free courses out of curiosity, either to obtain knowledge and skill (Kolowich, Coursera Takes a Nuanced View of MOOC Dropout Rates, 2013) or to satisfy their self-esteem (Wang \& Baker, 2015).

However, there are several who enrolls to obtain course certificate. For such learners, specialization certificate is available as an option after passing a set of courses and completing a final project. Afterwards, they can obtain a technical certificate by taking an official examination held by certain product certifier. Alternatively, they might want to submit their course certificates as credits and continue taking the remaining courses required to get a degree from a university. Some degree holders, such as Bachelor of Psychology or Accounting, even enrich their work experience and intend to be a certified professional by taking a professional certification held by professional association. On top of those needs, they want to seek jobs matching their acquired certificates and/or degrees. The hierarchy of these needs can be depicted as a needs ladder in Fig. 1. The arrows indicate the possible sequence to achieve them.

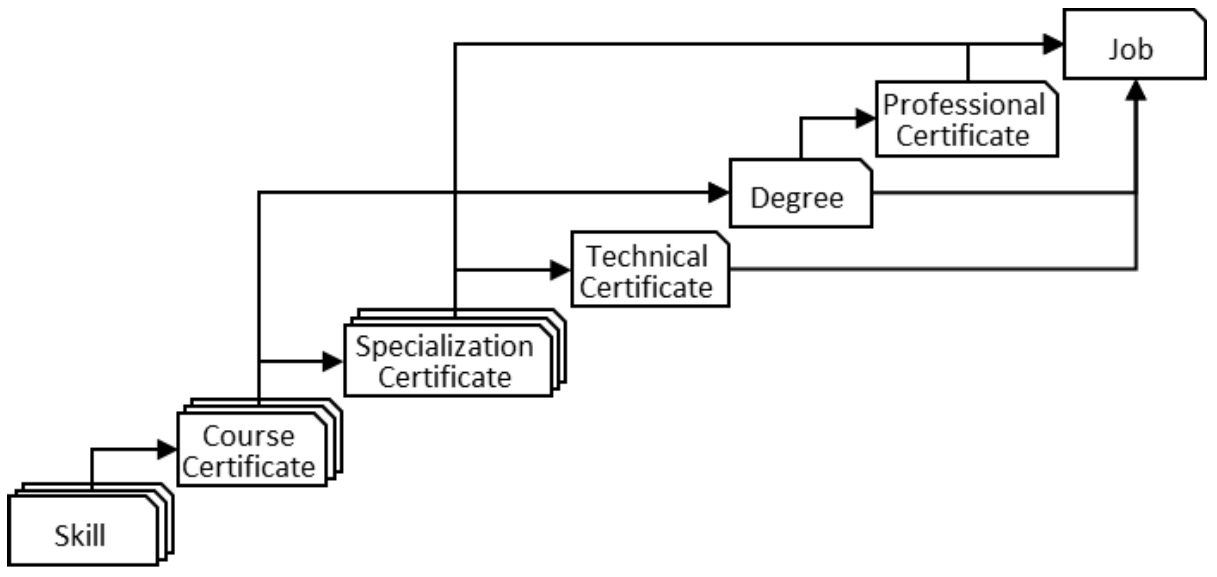

Fig. 1. The learners' needs ladder 


\section{Online Course Stakeholder}

\subsection{Stakeholders Identification}

Based on their theoretical framework of e-learning, Aparicio et al. divided e- learning systems stakeholders into 5 groups: Customer, Supplier, Board and Shareholder, Professional Association, and Special Interest Group [5]. However, based on needs analysis conducted in previous section, here the stakeholders of online courses are identified as: Learner, Instructor, University, Company/Organization, and Product Certifier. The role of Learner is to learn courses in order to achieve their needs. Instructor is responsible to create courses based on his/her expertise. University publishes their courses as credit earning units as well as granting degree for accomplished learners. Company and Organization design online training for their employees and create courses as a mean for recruiting qualified learners seeking for jobs. Product Certifiers are companies that grant technical certificate for Learner enrolled on their courses, such as Google, Cisco, and Microsoft.

These identified stakeholders alone are not sufficient to deliver online courses. They require the presence of Provider to establish and maintain online course services to serve as their interaction platform. The responsibility of Provider is to provide infrastructure and technology as a platform to ensure that online courses are publicly available. Additionally, even though Professional Association has no need for online courses, the system requires their presence to legitimate professional certification. As a matter of convenience, we also add Society as the source of learners and instructors.

\subsection{Stakeholders Relationship}

The next important issue after identifying stakeholders is to address the relationship between stakeholders. Learner can be any individual from Society or any employee from Company or other Organization. Instructor can be any expert from University, Company/Organization, or Society, who intend to create and teach their own courses. When learners seek a degree, they need to directly contact a University. University creates courses and possibly contact Company to obtain real technical data and practical problems as needed. This collaboration emerges in developing capstone projects which are based on real-world problems [26]. Learner seeks Professional/Technical Certificate needs to contact Professional Association or Product Certifier. Stakeholders, their roles, and the relationship among them can be depicted using context diagram as typically used in process modeling [27]. This relationship diagram is shown in Fig. 2.

Based on Fig. 2, Provider serves as the bridge connecting and overseeing all other stakeholders through their crucial role on maintaining online course services. However, it should be noted that there is no direct relationship between Professional Association and Provider due to lack of professional exam currently held through online course providers. This could be an opportunity for any Provider to build partnership with Professional Association in near future. 


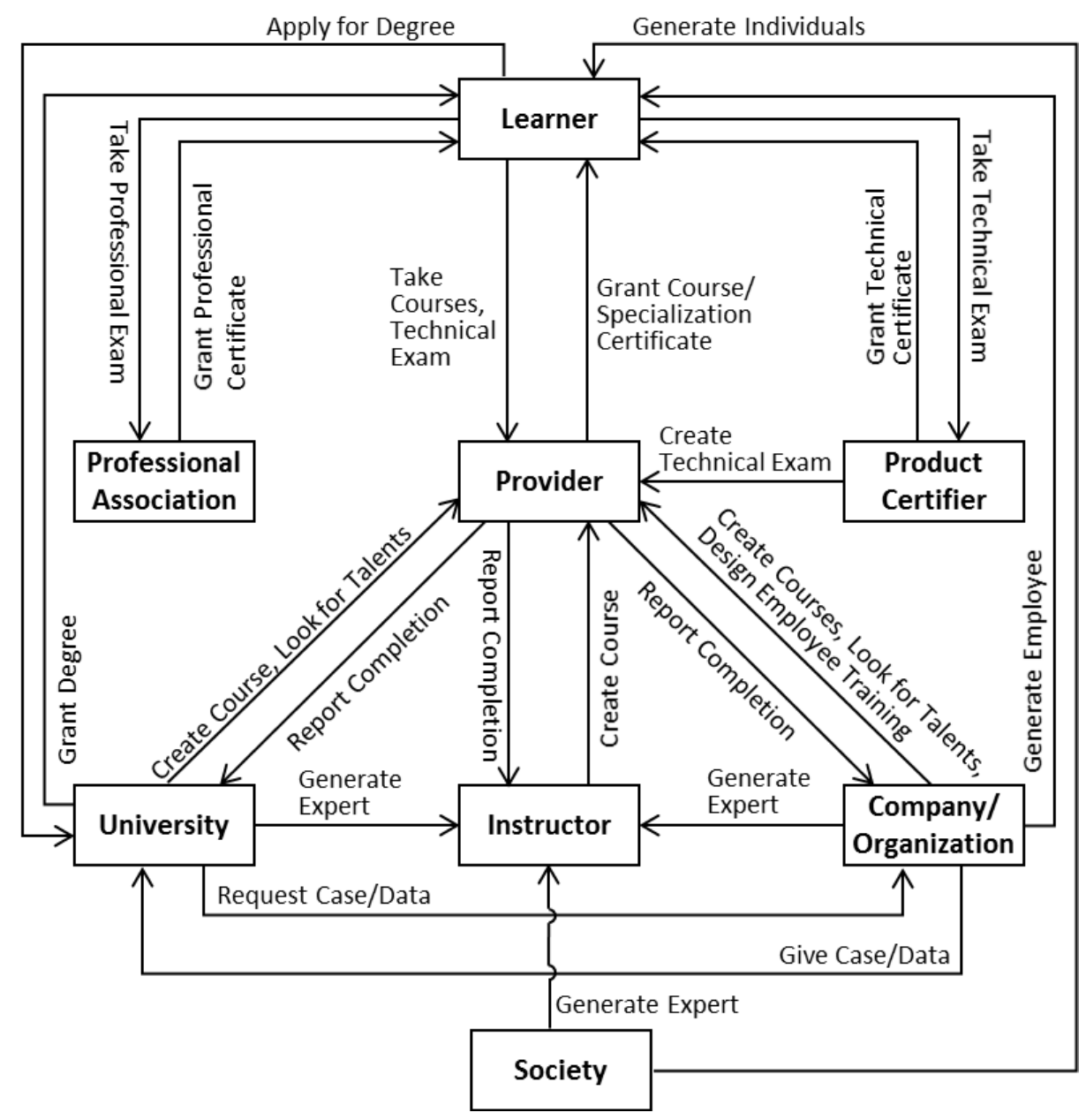

Fig. 2. Context Diagram of Online Course Services

This diagram fully describes Stakeholders' relationship in MOOC service. Based on the definition of COC service from previous section, the role of Provider is taken over by University since they maintained their own online course services. Meanwhile the context diagram for OD service only contains part of the above diagram focusing on granting degree for Learner. Therefore, COC and OD services can be concluded as subsets of MOOC service with fewer stakeholders and simpler relationships.

\section{$4 \quad$ Activity Flows of Online Course Services}

The next step in modelling online course services is to identify activity flows of online course services. Learners have variety of needs and each of those can be 
achieved through a corresponding series of activities maintained by Provider. The required activities for each need can be modelled as a flow diagram commonly used in any process modeling [27].

\subsection{Skill Development and Course Certification}

In the early year of online course services, only around $10 \%$ of learners in MOOC complete their courses, despite the high number of enrollments. Their main aim at that time is to explore contents of a course and move on to other courses [8, 24]. However, GetSmarter recently has claimed that approximately $90 \%$ of their learners complete the courses [28]. Despite those facts, these learners only intend no further than to develop their skill or to achieve a course certificate.

Enrolling in online course allows learners to learn its materials and complete the assessments to advance their own skill. Online course providers typically allow them to explore courses as many as possibly, either simultaneously or serially. However, they can obtain course certificate after attaining passing grade and paying certification fee. Activity flow required to develop skill and/or pursue course certificate are summarized in Fig. 3.

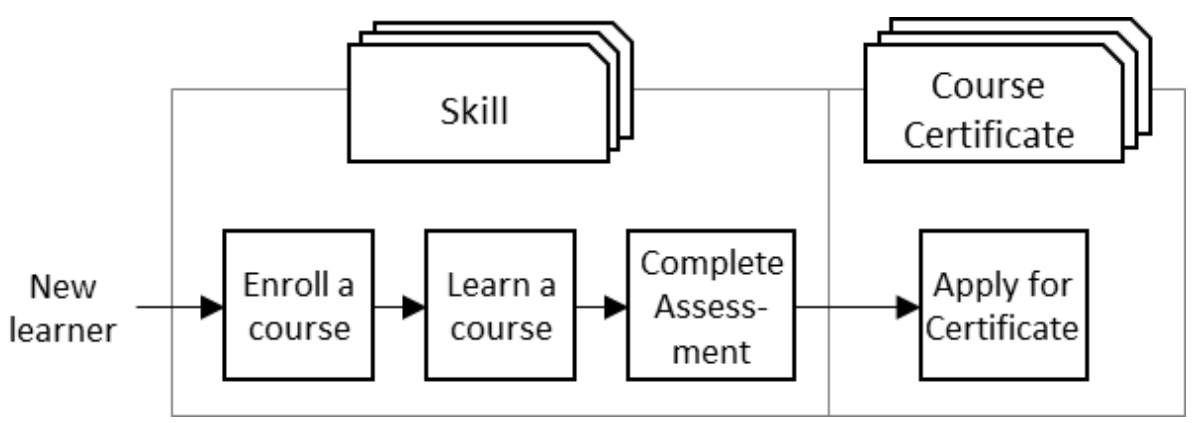

Fig. 3. Flow Diagram for Skill Development and Course Certification

\subsection{Specialization and Technical Certification}

To acquire more comprehensive and complex skill and knowledge, learners must complete a series of courses and a final project in a specialization program. To earn certificate, they must pass the grade requirement of each course, complete final project, and then pay the certification fee. More prestigious certification program is technical certification granted by Product Certifiers. In some cases, online course provider provides a preparation program for technical certification. For example, a specialization program on Android Developer designed by Google and delivered through Udacity can be taken as a preparation program for Android Developer Certification exam [23]. Activity flow required to obtain specialization and/or technical certificates are summarized in Fig. 4.

As illustrated in Fig. 4, there are several possible paths to achieve these certificates. Path comprises of only solid lines is for learners already possess course certificate(s) 


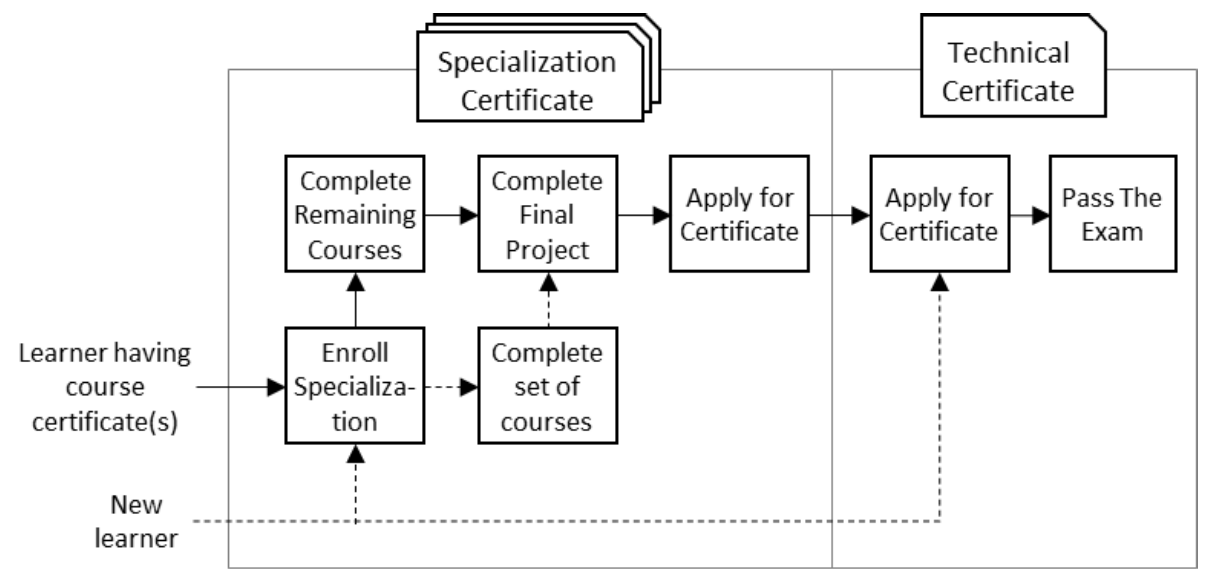

Fig. 4. Flow Diagram for Specialization and Technical Certification

and paths contain dashed lines are for new learners directly apply to specialization certificate and/or technical certificate. Learners previously completed some courses required in a specialization program only need to enroll in the remaining courses and final project. New learners can enroll in technical certification directly because there is no prerequisite to take technical certification exam.

\subsection{Degree Granting and Professional Certification}

It is possible for learners to pursue a degree through online course. There are numerous online courses officially approved by several universities. Successful completion of those coursers will be acknowledged as credits for earning a degree from affiliated University. After the completion, learners have the possibility to either complete the remaining courses by enrolling in University or continue pursuing online courses. Learners who choose online course, however, must complete special courses, which are courses especially maintained by University. Although these courses also delivered online, the evaluation and supervision are directly and rigorously handled by lecturers from University [29].

Degree of certain fields of study, such Psychology or Accounting, allow its holders to become professional in their fields after passing the requirement and examination held by related Professional Association. This type of certification program ensures the qualification of its holder to perform a professional job or task related to specific fields. The activity flow required to get degree and professional certificate are summarized in Fig. 5.

Fig. 5 illustrate several possible paths to achieve a degree or professional certificate, depending whether learners already possessed a certification from online courses or not. The paths containing only solid lines are the paths for those already have some certificates and the paths containing some dashed lines are for new learners without any certificate. Learners who have completed some online courses published by University can submit the certificates to University which publishes the courses as credits 


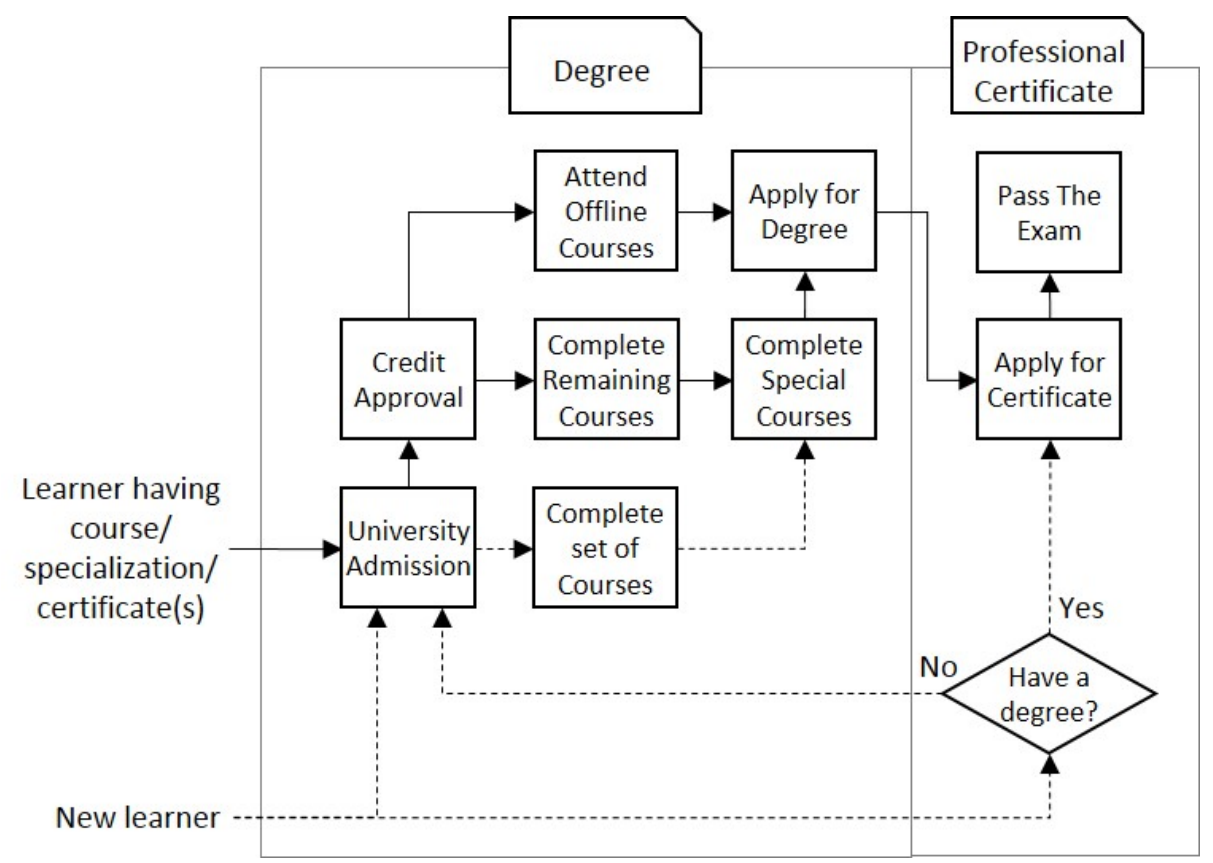

Fig. 5. Flow Diagram for University Degree Granting \& Professional Certification

earning, and if approved, they can continue to enroll the remaining courses required in the curriculum for a degree. After obtaining a degree, a learner who also wants to obtain a professional certificate must fulfill the minimum requirement and experience determined by Professional Association and pass the examination. New learners must register to a University as degree-seeking student before enrolling in online courses required to get a degree. A new learner who already hold a degree is allowed to apply for professional certification directly.

\subsection{Job Offering}

Online course also provides opportunities for learners to seek jobs through the Provider after completing at least specialization certification. Many companies and organizations partnering with Providers offer jobs to some talented learners based on their progress and achievement during the courses and assessments. This hiring partnership is already maintained by Udacity with forward-looking companies in the world such as Mercedes-Benz, AT\&T, NVIDIA, IBM, and many more [29]. Activities conducted by online course provider to offer a job to successful learners are very limited and are not well maintained yet by providers as summarized in Fig. 6 . 


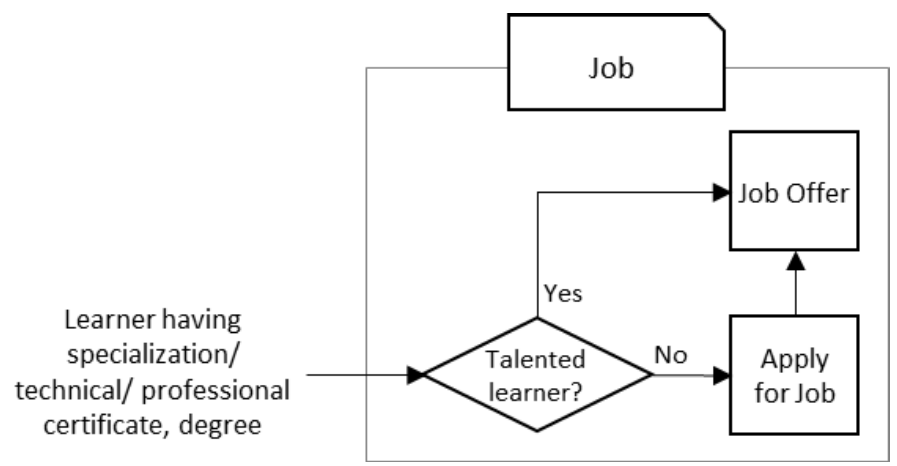

Fig. 6. Flow Diagram for Job Offering

\subsection{Continuation of Services}

All service models presented above can be combined into a continuation of services. Such continuing combination can be described by a flow diagram as shown in Fig. 7. There are many paths for learners to pursue their needs, depending on whether they already have specific needs in mind when enrolling in online courses. The paths comprise only solid lines are for learners gradually pursuing their needs in accordance with needs ladder, while paths contain some dashed lines are for learners seeking to satisfy their specific needs at a time.

\subsection{Entities Involved in Service Model}

In modelling online course services, it is necessary to show the relations of entities involved using Entity Relationship Diagram (ERD) (Dennis, Wixom, \& Roth, 2012). Stakeholders identified in previous section serve as the primary entities. The relations among these entities can be constructed through additional (secondary) entities identified in the activities flow diagrams of previous section, which are: Courses, Course/Specialization Certificate, Technical Certificate, Degree, Professional Certificate, and Job. The relationship among entities in online course service model is depicted in Fig. 8. In the figure there is an additional secondary entity called Talent which represent talented learners identified by Provider among Learner to be promoted to University and/or Company/Organization.

The boxes represent entities involved in online course services with secondary entities written in italic and the arrows represent the relationship among entities. Even though Society is identified as one of the stakeholders in the context diagram, it is not included in the diagram because it does not require any secondary entity to be associated with other stakeholders. From this diagram, Course is the most involved entity in online course services. It is therefore can be assumed that Course is the main attraction in online course which can be utilized of Provider to attract Learner. In other words, Provider will have more opportunity to reach wider participants by delivering Course from multiple stakeholders and promoting it as the best way for Learner in achieving their needs. 
Paper-Modelling Online Course Services and Comparison of its Major Providers

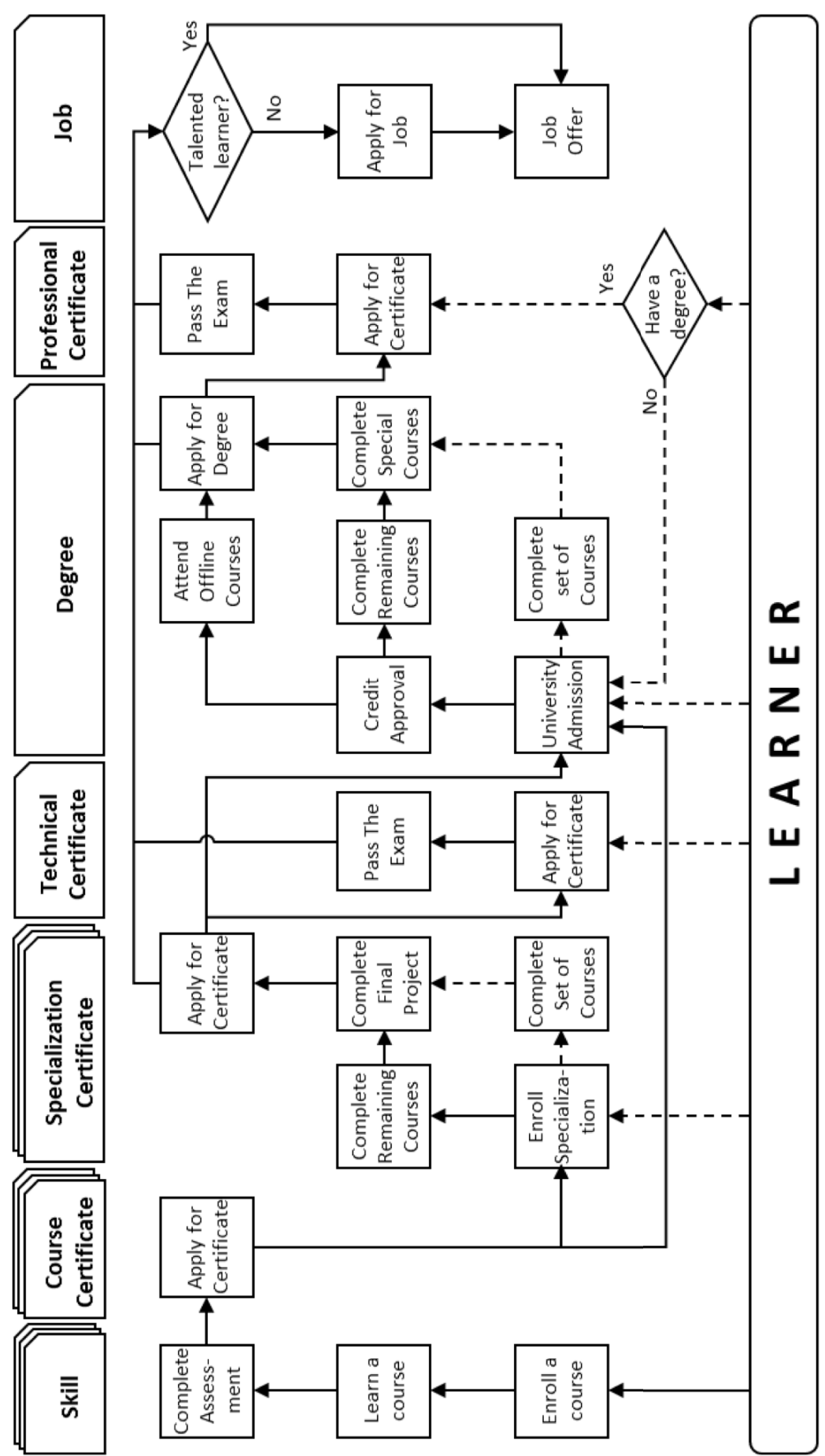

Fig. 7. Flow Diagram of Overall Online Course Services 


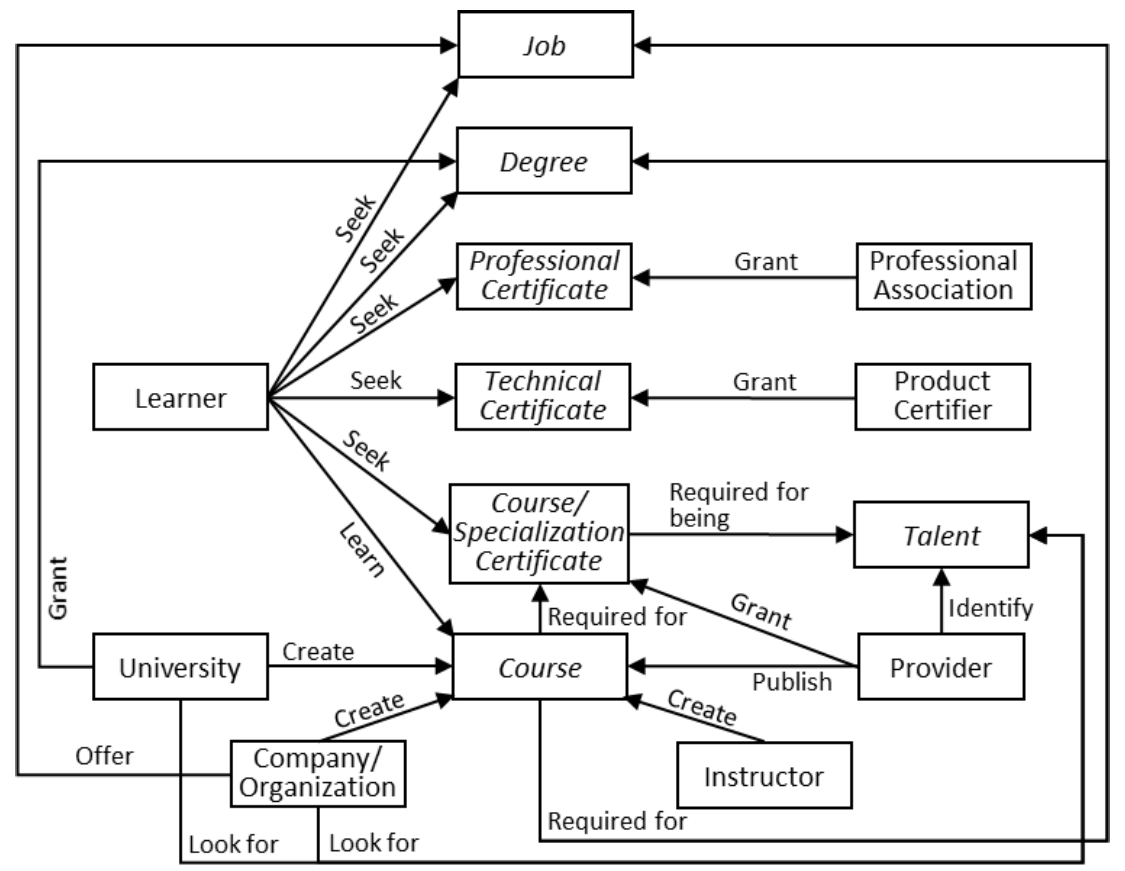

Fig. 8. Entity Relationship Diagram of Online Course Services

\section{Service Comparison of Major Online Course Providers}

Based on the proposed service model, the comparison of major online course providers can be drawn. Coursera, edX, Udacity, Udemy, FutureLearn, and GetSmarter represent MOOC Provider, while ASU Online represent COC Provider and $2 \mathrm{u}$ represent OD Provider.

Coursera offers numerous open courses created by multiple universities. Learner can access all course materials and assessments for free, but need to fulfill the passing grade and pay a certification fee to obtain a course certificate. Coursera also offers Specialization Certification, a set of career-oriented courses and a project to achieve deeper understanding and higher skills that may end up with Degree. University of Illinois at Urbana-Champaign for example offers several online-degree program through Coursera. Additionally, Coursera offers training and development program for employees of Companies/Organizations which can choose courses specifically matched its needs [30].

Similarly, edX offers four services: Open Course, Course Certificate, Professional Certificate, edX Credit, and XSeries program. Professional Certificate referred in here is different than one granted by Professional Association as previously explained; it is more similar to Specialization Certificate in Coursera. Learner can also obtain credits to pursue Degree from a participating university by enrolling in a series of its undergraduate or graduate courses through edX Credit program. XSeries program offers 
deep understanding of interesting and popular subjects. In addition, edX offers employee training and development program to Company/Organization [31].

Udacity offers three services: Open Course, Course Certificate, and Nano Degree. Nano Degree program is a series of technical courses designed by experts from world top companies. It is not a degree by conventional mean, rather similar to Specialization Certificate. Learner completed this program has an opportunity to get job offer from partner companies. Udacity also offers employees training and development program to Company/Organization. Additionally, Udacity provides a free-service for companies to hire prospectus/talented Udacity's learners as their employees [32].

Udemy offers Open Course and Course Certificate for Learner and employee training and development program for Company/Organization. Udemy's available courses are not designed for degree taking credit, but for improving technical skills or preparing technical certification exams. In that matter, Udemy provides a platform for individual experts not affiliated with universities or companies to create courses to be offered for free or for a tuition [33].

FutureLearn offers free courses, course certification, specialization, and onlinedegree for Learner [34]. GetSmarter focuses on providing career-oriented course certification for Learner and employee online training for Company [35].

Some universities offer online courses for their registered students. One of them is Arizona State University through its ASU Online. ASU Online offers undergraduate/graduate degree, graduate/undergraduate certificate, undergraduate minor, and undergraduate exploratory. The degree program is available for degree-seeking learners from any countries, the certificate program is a set of courses for preparing professional examination or work, the minor program is designed for earning credits before taking a real-degree program, and the exploratory program is designed for learners from high school who want to explore variety of courses matching their interest. ASU Online do not offer open courses (Arizona State University, 2017).

On the other hand, $2 u$ is an Online-Degree Provider. While ASU online-degree is offered and developed only by Arizona State University, $2 u$ partners with multiple colleges and universities to develops courses and offers online degrees ( $2 u$ Inc., 2017). The service comparison among several online course providers is summarized in Table 2. .

In order to attract learners, each Provider has its own strategy. While Coursera, edX, FutureLearn, GetSmarter, and $2 u$ have a strong partnership with University in providing academic courses, Udacity build a relation with Companies in offering technical certification and job offer for their learners. ASU Online only offers specialization certificate and degree for its students. Unlike the other providers, Udemy has its own uniqueness by allowing any individual experts to be instructor and create his/her own courses. However, despite the uniqueness of each provider, major drawbacks drawn from this comparison are that neither of these major providers offers professional certificate program and only Udacity offers technical certificate program and job opportunity. 
Table 2. Service Comparison of Major Online Course Providers

\begin{tabular}{|c|c|c|c|c|c|c|c|c|}
\hline Services & Uूँ & $\stackrel{\breve{z}}{\mathrm{z}}$ & $\begin{array}{l}\frac{3}{0} \\
\frac{\pi}{2} \\
0 \\
0\end{array}$ & $\frac{\vec{\Xi}}{\vec{D}}$ & 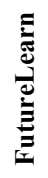 & 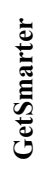 & 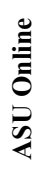 & $\Xi$ \\
\hline \multicolumn{9}{|l|}{ For Learner } \\
\hline Skill development & $\mathrm{V}$ & $\mathrm{V}$ & $\mathrm{V}$ & $\mathrm{V}$ & $\mathrm{V}$ & & & \\
\hline Course certificate & $\mathrm{V}$ & $\mathrm{V}$ & $\mathrm{V}$ & $\mathrm{V}$ & $\mathrm{V}$ & $\mathrm{V}$ & & \\
\hline Specialization certificate & $\mathrm{V}$ & $\mathrm{V}$ & $\mathrm{V}$ & & $\mathrm{V}$ & & $\mathrm{V}$ & \\
\hline Technical certificate & & & $\mathrm{V}$ & & & & & \\
\hline \multicolumn{9}{|l|}{ Professional certificate } \\
\hline Degree & $\mathrm{V}$ & & & & $\mathrm{V}$ & & $\mathrm{V}$ & $\mathrm{V}$ \\
\hline Job & & & $\mathrm{V}$ & & & & & \\
\hline \multicolumn{9}{|l|}{ For Instructor } \\
\hline Create courses & & & & $\mathrm{V}$ & & & & \\
\hline \multicolumn{9}{|l|}{ For University } \\
\hline Create courses & $\mathrm{V}$ & $\mathrm{V}$ & $\mathrm{V}$ & & $\mathrm{V}$ & $\mathrm{V}$ & & $\mathrm{V}$ \\
\hline Offer credit courses & $\mathrm{V}$ & $\mathrm{V}$ & & & $\mathrm{V}$ & & & \\
\hline Offer degree & $\mathrm{V}$ & & & & $\mathrm{V}$ & & & $\mathrm{V}$ \\
\hline \multicolumn{9}{|l|}{ For Company/Organization } \\
\hline Employee training/development & $\mathrm{V}$ & $\mathrm{V}$ & $\mathrm{V}$ & $\mathrm{V}$ & $\mathrm{V}$ & $\mathrm{V}$ & & \\
\hline Hire employee & & & $\mathrm{V}$ & & & & & \\
\hline Create courses & & $\mathrm{V}$ & $\mathrm{V}$ & $\mathrm{V}$ & $\mathrm{V}$ & & & \\
\hline \multicolumn{9}{|l|}{ For Product Certifier } \\
\hline $\begin{array}{l}\text { Create preparation courses for technical } \\
\text { certification }\end{array}$ & & & $\mathrm{V}$ & & & & & \\
\hline Technical certification exam & & & $\mathrm{V}$ & & & & & \\
\hline
\end{tabular}

\section{Conclusions}

Online course opens up many opportunities to fulfill the needs of those who are limited by access, time, and financial availability to educate themselves. This paper has presented that Learner and other stakeholders have a variety of needs for online course and providers possess the key role in bridging those needs. From the models presented in this paper, it is possible to make comparison among online course providers. The comparison shows that to reach wider participants, Provider needs to maximize the utilization of their courses as the best resources for Learner to achieve their needs. Most importantly, this comparison concludes that most Provider only 
focus on providing services for skill development, course/specialization certificate, and degree. This implies that services for professional/technical certification and job have yet to be explored. To realize these yet unfulfilled services, Provider should convince other stakeholders to partner in delivering such services. In other words, the opportunities for online course providers to expand their services by involving more stakeholders are still widely open. As a future research, this study can be expanded to a more comprehensive model and comparison by including financial and technical aspects of online course services. Another potential future research is expanding the number of online course providers studied.

\section{$7 \quad$ References}

[1] E. Brynjolfsson and A. McAfee, The Second Machine Age: Work, Progress, and Prosperity in a Time of Brilliant Technologies, New York: W. W. Norton \& Company, Inc., 2014.

[2] Wikipedia, "Massive open online course," 12 April 2017. [Online]. Available: https://en.wikipedia.org/wiki/Massive open online course. [Accessed 28 April 2017].

[3] X. Holdaway, "Major Players in the MOOC Universe," 29 April 2013. [Online]. Available: $\quad$ http://www.chronicle.com/article/Major-Players-in-the-MOOC/138817. [Accessed 27 April 2017].

[4] D. L. Clinefelter and C. B. Aslanian, "ONLINE COLleGE STUDENTS 2017: Comprehensive Data on Demands and Preferences," The Learning House, Inc., Louisville, 2017.

[5] M. Aparicio, F. Bacao and T. Oliveira, "An e-Learning Theoretical Framework," Educational Technology \& Society, p. 292-307, 2016.

[6] M. Aparicio, F. Bacao and T. Oliveira, "MOOC's Business Models: Turning Black Swans into Gray Swans," in International Conference on Information Systems and Design of Communication, Lisbon, 2014. https://doi.org/10.1145/2618168.2618175

[7] C. Zhenghao, B. Alcorn, G. Christensen, N. Eriksson, D. Koller and E. J. Emanuel, "Who's Benefiting from MOOCs, and Why," Harvard Business Review, vol. 25, 22 September 2015.

[8] D. F. Onah, J. Sinclair and R. Boyatt, "Dropout rates of massive open online courses: behavioural patterns," in 6th International Conference on Education and New Learning Technologies, Barcelona, 2014.

[9] T. Dillahunt, B. Chen and S. Teasley, "Model thinking: demographics and performance of MOOC students unable to afford a formal education," in Proceedings of the first ACM conference on Learning@ scale conference, 2014. https://doi.org/10.1145/2556 325.2567851

[10] L. Pappano, "The Boy Genius of Ulan Bator," 13 September 2013. [Online]. Available: http://www.nytimes.com/2013/09/15/magazine/the-boy-genius-of-ulan-bator.html. [Accessed 27 April 2017].

[11] M. Chafkin, "Udacity's Sebastian Thrun, Godfather Of Free Online Education, Changes Course," 14 November 2013. [Online]. Available: https://www.fastcompany.com/30 21473/udacity-sebastian-thrun-uphill-climb. [Accessed 26 May 2017].

[12] S. Kolowich, "American Council on Education Recommends 5 MOOCs for Credit," 7 February 2013. [Online]. Available: http://www.chronicle.com/article/American-Councilon-Education/137155/. [Accessed 27 April 2017]. 
[13] T. Lewin, "Universities Abroad Join Partnerships on the Web," 20 February 2013. [Online]. Available: http://www.nytimes.com/2013/02/21/education/universities-abroadjoin-mooc-course-projects.html. [Accessed 27 April 2017].

[14] R. Kelly, "European MOOC Platform Expands to 5 U.S. Universities," 14 February 2017. [Online]. Available: https://campustechnology.com/articles/2017/02/14/european-moocplatform-expands-to-5-us-universities.aspx. [Accessed 27 April 2017].

[15] J. Haywood, A. Woodgate and D. Dewhurst, "Reflections of an early MOOC provider: Achievements and future directions," in MOOCs and Open Education Around the World, Routledge, 2015, p. 89.

[16] T. Onink, "Georgia Tech, Udacity Shock Higher Ed With \$7,000 Degree," 15 May 2013. [Online]. Available: https://www.forbes.com/sites/troyonink/2013/05/15/georgia-techudacity-shock-higher-ed-with-7000-degree/. [Accessed 27 April 2017].

[17] D. Douglas-Gabriel, "Purdue acquires for-profit Kaplan University," The Washington Post, 27 April 2017. [Online]. Available: https://www.washingtonpost.com/news/gradepoint/wp/2017/04/27/purdue-acquires-for-profit-kaplan-university/. [Accessed 11 May 2017].

[18] E. Carson, "How MOOCs are flattening corporate training and education," 20 June 2014. [Online]. Available: http://www.techrepublic.com/article/how-moocs-are-flatteningcorporate-training-and-education/. [Accessed 26 April 2017].

[19] D. Shah, "How Does Coursera Make Money?," 15 October 2014. [Online]. Available: https://www.edsurge.com/news/2014-10-15-how-does-coursera-make-money. [Accessed 28 March 2017].

[20] J. Vincent, "Google just published a free, three-month course on deep learning," The Verge, 22 January 2016. [Online]. Available: https://www.theverge.com/2016/1/22/1081 3984/google-deep-learning-udacity. [Accessed 10 June 2017].

[21] British Council, "Educating through MOOC," 2017. [Online]. Available: http://www.britishcouncil.org.np/educating-through-MOOC. [Accessed 27 May 2017].

[22] Udacity, Inc., "Associate Android Developer Exam," 2017. [Online]. Available: https://www.udacity.com/google-certifications. [Accessed 11 June 2017].

[23] Udacity, Inc., "Android Developer Nanodegree by Google," 2017. [Online]. Available: https://www.udacity.com/course/android-developer-nanodegree-by-google--nd801. [Accessed 11 June 2017].

[24] S. Kolowich, "Coursera Takes a Nuanced View of MOOC Dropout Rates," 8 April 2013. [Online]. Available: http://www.chronicle.com/blogs/wiredcampus/coursera-takes-a-nuanc ed-view-of-mooc-dropout-rates/43341. [Accessed 25 May 2017].

[25] Y. Wang and R. Baker, "Content or platform: Why do students complete MOOCs?," Journal of Online Learning and Teaching, vol. 11, no. 1, p. 17, 2015.

[26] T. Dodd, "Coursera MOOC online capstone offers real-world projects," 16 February 2015. [Online]. Available: http://www.afr.com/news/policy/education/coursera-mooc-onlinecapstone-offers-realworld-projects-20150212-13dkm0. [Accessed 27 April 2017].

[27] A. Dennis, B. H. Wixom and R. M. Roth, Systems Analysis \& Design, 5th ed., New Jersey: John Wiley \& Sons, Inc., 2012.

[28] C. Howard, "EdTech Giant 2U Acquires GetSmarter For \$103 Million," Forbes, 2 May 2017. [Online]. Available: https://www.forbes.com/sites/carolinehoward/2017/05/02/ edtech-giant-2u-acquires-getsmarter-for-103-million/. [Accessed 11 May 2017].

[29] Udacity, Inc., "Hiring Partners," 2017. [Online]. Available: https://www.udacity.com/ hiring-partners. [Accessed 31 July 2017].

[30] Coursera Inc., "Coursera," 2017. [Online]. Available: https://www.coursera.org. [Accessed 27 May 2017]. 
[31] edX Inc., "edX," 2017. [Online]. Available: https://www.edx.org/. [Accessed 25 May 2017].

[32] Udacity Inc., "Udacity," 2017. [Online]. Available: https://www.udacity.com/. [Accessed 27 May 2017].

[33] Udemy, "Udemy," 2017. [Online]. Available: https://www.udemy.com/. [Accessed 27 May 2017].

[34] FutureLearn, "FutureLearn," 2017. [Online]. Available: https://www.futurelearn.com/. [Accessed 27 May 2017].

[35] 2u Inc., "GetSmarter," 2017. [Online]. Available: https://www.getsmarter.com/. [Accessed 27 May 2017].

[36] Arizona State University, "ASU Online," 2017. [Online]. Available: http://asuonline.asu.edu/. [Accessed 27 May 2017].

[37] 2u Inc., 2017. [Online]. Available: https://2u.com/. [Accessed 27 May 2017].

\section{Authors}

Abdullah Alkaff is a professor at Systems and Cybernetics Laboratory, Electrical Engineering Department, Institute of Technology Sepuluh Nopember (ITS), Surabaya, Indonesia. He graduated from the University of Florida and was a visiting professor at Syracuse University. His interest in e-learning was developed while he was a senior advisor to the Minister of Education and Culture, Republic of Indonesia, for empowering ICT in learning and education management as one of his many duties.

M. Nur Qomarudin is a research associate at Systems and Cybernetics Laboratory, Electrical Engineering Department, ITS. He was involved in the development of SHARE ITS, the e-learning platform of ITS. With Bilfaqih, they together wrote several guidelines for developing online courses.

Sylmina D. Alkaff is a lecturer at Biomedical Engineering Department, Institute of Technology Sepuluh Nopember (ITS), Surabaya, Indonesia. She tried and participated in many online courses from several providers when she was a graduate student at Northwestern University.

Yusuf Bilfaqih is lecturer at System and Cybernetics Laboratory, Electrical Engineering Department, ITS. He is one of the architects and conceptual designers of SHARE ITS, the e-Learning platform of ITS. He actively researches and trains online learning and assessment methods and developed many online courses and assessments. With Qomaruddin, he authored several guidelines for developing online courses.

Article submitted 23 August 2017. Published as resubmitted by the authors 25 October 2017. 